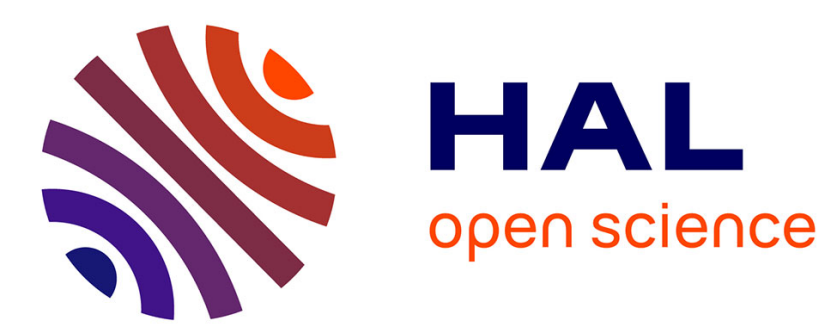

\title{
Architectured interfaces and electrochemical modelling in an anode supported SOFC
}

Maya Geagea, Jian Ouyang, Bo Chi, Francesco Delloro, Anthony Chesnaud, Armelle Ringuedé, Michel Cassir, Alain Thorel

\section{- To cite this version:}

Maya Geagea, Jian Ouyang, Bo Chi, Francesco Delloro, Anthony Chesnaud, et al.. Architectured interfaces and electrochemical modelling in an anode supported SOFC. SOFC-XIV: Anodes 2, Jul 2015, Glasgow, United Kingdom. 10.1149/06801.2961ecst . hal-01199302

HAL Id: hal-01199302

https://hal-mines-paristech.archives-ouvertes.fr/hal-01199302

Submitted on 15 Sep 2015

HAL is a multi-disciplinary open access archive for the deposit and dissemination of scientific research documents, whether they are published or not. The documents may come from teaching and research institutions in France or abroad, or from public or private research centers.
L'archive ouverte pluridisciplinaire HAL, est destinée au dépôt et à la diffusion de documents scientifiques de niveau recherche, publiés ou non, émanant des établissements d'enseignement et de recherche français ou étrangers, des laboratoires publics ou privés. 
Architectured Interfaces And Electrochemical Modelling In An Anode Supported SOFC

Maya Geagea $^{\mathrm{a}}$, Jian Ouyang ${ }^{\mathrm{ab}}$, Bo Chi $^{\mathrm{b}}$, Francesco Delloro $^{\mathrm{a}}$, Anthony Chesnaud $^{\mathrm{a}}$, Armelle Ringuedé ${ }^{\mathrm{c}}$, Michel Cassir ${ }^{\mathrm{c}}$, Alain Thorel $^{\mathrm{a}}$

${ }^{a}$ Centre des Matériaux, MINES-ParisTech, PSL, UMR CNRS 7633, BP 87, 91003 Evry Cedex, France

${ }^{\mathrm{b}}$ HUST-Huazong University of Science and Technology, ICARE Institute, Wuhan 430074, China

${ }^{\mathrm{c}}$ I2E, Chimie-ParisTech, PSL, UMR CNRS 8247, 11 rue Pierre et Marie Curie 75231 Paris Cedex 05

\begin{abstract}
Increasing the SOFC performances is many-fold: i/ at low current density, through the enhancement of the catalytic properties of the electrodes, ii/ at the ohmic loss region, through lower resistance, iii/ at the high current density region, via the optimization of the electrodes microstructure. The present work proposes to explore how the corrugation of electrode/electrolyte interfaces impacts the performances of SOFCs.

Taking ideas from the battery community, this approach was applied to the anode/electrolyte interface of a SOFC based on standard compositions. Patterning of this interface was achieved with different geometries at the $10-100 \mu \mathrm{m}$ scale by cold pressing. Thin electrolyte layers have been deposited on top of these architectures by different techniques. In parallel, an electrochemical model was carried out and implemented throughout the interface in FEM (finite element method) with COMSOL Multiphysics. The results showed a $25 \%$ increase in the total current density for a certain ellipsoid geometry.
\end{abstract}

\title{
I.Introduction
}

Solid Oxide Fuel cells are old concept, high efficiency energy conversion devices, environmentally friendly with the advantage of being flexible to multi fuel usage if compared with other devices. However, its commercialization is still retarded due to several challenges facing its development. One of the biggest drawbacks of SOFC is low durability and too high manufacturing costs along with low power densities. Recent studies are actually focusing on enhancing SOFC's performance. Results show the correlation between the TPB, in particular at the interface; where the electrochemical reactions take place and the power density of an SOFC. Therefore, mesoscale geometry control of the interface is a key topic especially in designing the porous electrodes of an SOFC. Hence, porous electrodes must have appropriate microstructures that increase the density of reaction sites (TPB), allow high gas diffusion and establish high electrical conductivity.

\section{II.Concept of electrode-electrolyte patterned interface}

Electrochemical reactions in solid oxide fuel cells occur at the Triple Phase Boundaries (TPB) where the three separate percolating phases interact; electron conducting, ion conducting and gaseous one. Generally, TPBs are located at the electrode-electrolyte interface. In the case of composite electrode, TPBs are distributed all over the volume of the porous layer, but not all of them contribute to the overall current density, thus not all of TPBs are equally active according to A.Martinez (1). According to recent understanding, these electrochemical reactions mostly occur at the vicinity of anode-electrolyte interface (2). The 
effective zone is estimated to extend few microns away from the electrolyte in the case of cermet anodes (3). Therefore, a high volumetric density of active TPBs in the effective thickness (4) of the electrode is necessary to attain high power densities. Due to its crucial role in the performance of the assembly, different ways of enhancing TPB density have been investigated: several studies (5) consisted in macroscopic scales (>1 mm) shifting from planar to tubular shapes, but disadvantages were for both configurations (yet lower for planar SOFCs). Other studies (6-8) focused on a microscopic scale. Here, modifications in the microstructure are achieved using nanoparticles near the interface. Performances are increased at the price of problems of durability in long-term usage. Recently, a third path for improving performances has been proposed, consisting in the mesoscopic scale patterning of the electrolyte-electrode interface. "Mesoscopic" means in this context the intermediate scales ranging between the geometrical (e.g. thickness of the assembly) and the microstructural levels (e.g. density of active TPBs). Konno et al (9) suggested a mesoscale-structure control to increase the active zone in the electrode by changing the shape of the interface. The suggested structure should be larger (between 10 to $100 \mu \mathrm{m}$ ) than the effective active reaction zone of electrode. Results showed that the mesoscale-grooved structure contributed in enhancing the cell's performance. H.Iwai et al. $(3,10)$ introduced a non-dimensional number which estimates the effectiveness of the expansion of the interface area. A value less than one indicate the possibility of enhancing the power density by means of shape modifications of the electrodeelectrolyte interface. Based on J.Nam's (11) micro-scale model, the evaluation of the charge transfer current density per unit length of TPBs has been carried out. Comparing experimental results with numerical simulations, $10 \%$ improvement of current density has been observed in the case of the patterned cathode-electrolyte interface. Konno et al(12) showed that the corrugated mesoscale structure of anode-electrolyte interface enhanced the cell's performance. A 59\% enhancement in cell's power was achieved with an interface enlargement factor of 1.73. This increase in performance wasn't possible in the case of low porosity in the anode. F.Delloro (13) focused on patterned cathode-electrolyte interfaces in a modeling study using the finite element method. It was found that in intermediate conditions, i.e. outside the ohmic and the kinetic regimes where, respectively, ohmic and activation overpotential dominates over the others, patterned interface would positively affect the performance of the assembly. The architectured electrolyte permits a better arrangement of the local flow field of the ionic species, resulting in the reduction of global ionic transport losses in the electrode and a higher current at fixed voltage with respect to standard flat interfaces.

\section{III.Modeling}

A 2-D finite element method (FEM) was carried out to simulate an anode supported SOFC in order to obtain its electrochemical characteristics. The PEN (positive-electrolyte-negative) assembly was composed by three adjacent domains: the composite cathode (porous LSM/YSZ), the electrolyte (dense YSZ) and a cermet anode (porous Ni/YSZ). Excluding the flat reference case, the electrolyte-electrode interfaces were geometrically patterned. Three different kinds of pattern were tested in the simulation (rectangle, triangle and ellipse as shown in Fig 1 left). A planar 2D model with periodic conditions on the side boundaries was used. This modeling abstraction is equivalent, in $3 \mathrm{D}$, to an infinitely repeating unit cell. The object extends infinitely also in the extruded dimension A portion of this infinite domain is shown in Fig. 1 (left). The upper domain, $50 \mu \mathrm{m}$ thick, is the cathode. The electrolyte, $80 \mu \mathrm{m}$ thick here, presents an elliptic pattern. The anode, $500 \mu \mathrm{m}$ thick, is at the bottom. 

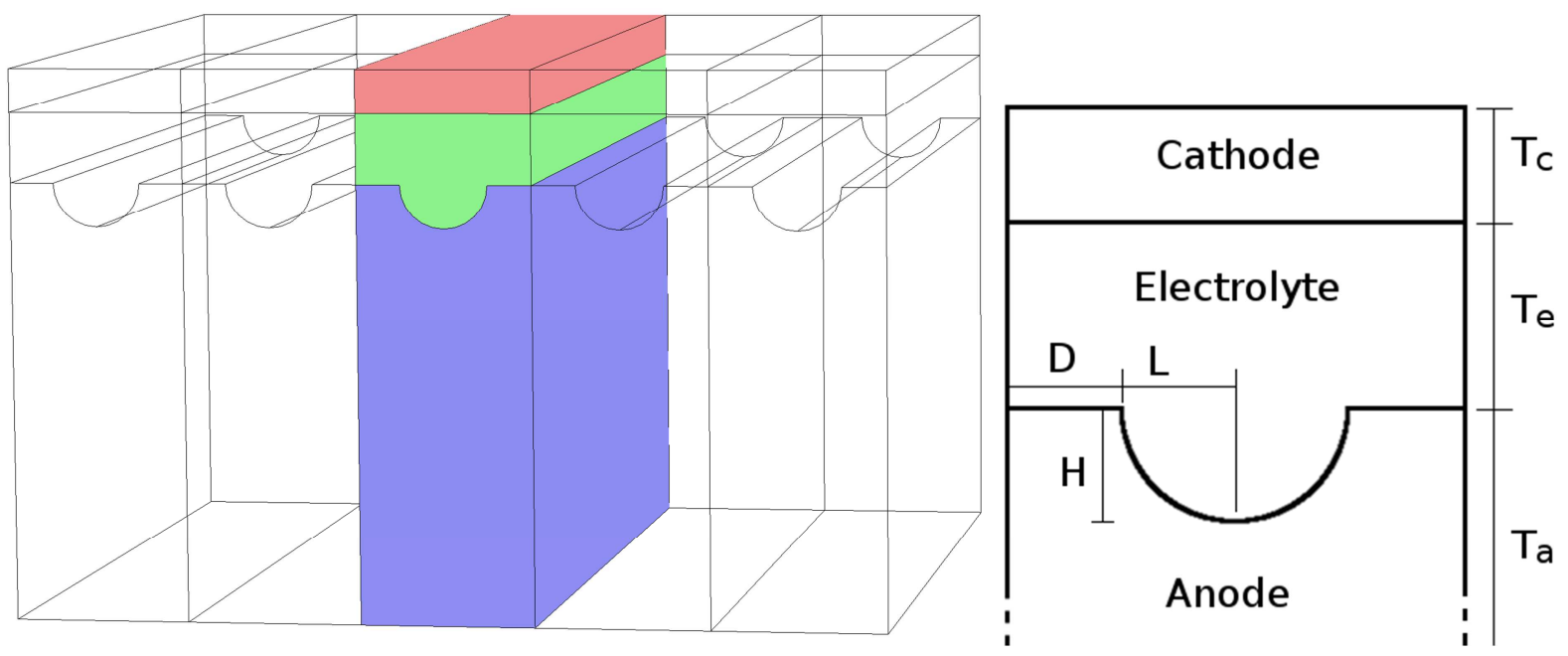

Figure.1 On the left, the assembly represented by $2 \mathrm{D}$ simulation domains. On the right, geometrical parameters.

The set of geometrical parameters defining the simulation domain are listed in Table I and shown in Figure.1 on the right. Electrode thicknesses (Tc and Ta) were kept constant, while the other parameters varied. All the possible combinations were tried for each pattern kind. For the flat reference case, so, two simulations $(\mathrm{Te}=50$ and $80 \mu \mathrm{m})$ were performed, while, e.g. for the elliptic pattern, a total of 96 simulations was done.

TABLE I. Geometrical parameters (see Figure.1, right).

\begin{tabular}{l|l|l|l}
\multicolumn{1}{c|}{ Parameter } & \multicolumn{1}{c|}{ Values [Units] } & \multicolumn{1}{c}{ Parameter } & \multicolumn{1}{c}{ Values [Units] } \\
\hline Tc (cathode thickness) & $50[\mu \mathrm{m}]$ & Pattern height $(\mathrm{H})$ & $10,50,100,200[\mu \mathrm{m}]$ \\
\hline Te (electrolyte thickness) & $80,50[\mu \mathrm{m}]$ & Pattern length $(\mathrm{L})$ & $5,10,50,100[\mu \mathrm{m}]$ \\
\hline Ta (anode thickness) & $500[\mu \mathrm{m}]$ & Pattern distance $(\mathrm{D})$ & $5,10,50[\mu \mathrm{m}]$ \\
\hline
\end{tabular}

The model is based on the following assumptions:

1) Steady state: variables are independent of time.

2) Temperature is uniform $\left(800^{\circ} \mathrm{C}\right)$ across the whole assembly.

3) Materials are treated as homogenized continua: effective conductivities are used in composites electrode to model the transport of ions, electrons and gas species.

4) Electronic potential throughout electrodes is constant. In the anode, electronic potential is 0 and the cathode electronic potential is the cell operating voltage E. As electronic conductivities of $\mathrm{Ni}$ and LSM are about 4 orders of magnitude larger than YSZ ionic conductivity (14), electronic potential drop through electrodes can be neglected.

5) A standard Butler-Volmer electrochemical kinetics is applied. Processes like absorption, dissociation and migration are neglected.

\section{$\underline{\text { Constitutive equations }}$}

Ionic transport, in both electrodes and in the electrolyte, can be described by the following governing equation:

$$
\nabla \cdot\left(\sigma_{Y S Z} \nabla u\right)=B i_{V}
$$


where $u$ is the ionic potential and $\sigma_{Y S Z}$ the ionic conductivity. Different values (see Table II) (11) where taken for the dense YSZ in the electrolyte $\left(\sigma_{\mathrm{YSZ}}^{0}\right)$ and the porous one in the electrodes $\left(\sigma_{\text {YSZ }}^{\text {eff }}\right)$. The right hand side of the equation, namely the source/sink term, couples ionic transport with the electrochemical reaction rates. $B$ equals 0 in the electrolyte, -1 in the anode and 1 in the cathode and $i_{V}$ is the volumetric current density, proportional to the local reaction rate.

The Dusty Gas Model (DGM) (15), (16) is used to model the gas transport. A binary system of gas species is considered in both electrodes $\left(\mathrm{H}_{2}-\mathrm{H}_{2} \mathrm{O}\right.$ in the anodic compartment, $\mathrm{O}_{2}-\mathrm{N}_{2}$ in the cathodic one). For each gas species $i$ in the compartment, the following governing equation can be derived:

$$
\nabla \cdot\left(\frac{\mathrm{k}_{i, 1}}{\mathrm{RT}} \nabla P_{i}\right)+\nabla \cdot\left(\frac{\mathrm{k}_{2}}{\mathrm{RT}} \nabla P_{\mathrm{T}}\right)=S_{i}
$$

where subscript $i$ runs either in $\left(\mathrm{H}_{2}, \mathrm{H}_{2} \mathrm{O}\right)$ or in $\left(\mathrm{O}_{2}, \mathrm{~N}_{2}\right), \mathrm{R}$ is the ideal gas constant, $\mathrm{T}$ the working temperature, $P_{i}$ is the partial pressure of species $i, P_{\mathrm{T}}$ the total pressure. $\mathrm{S}_{i}$ is the molar consumption or production rate due to electrochemical reactions $\left(S_{\mathrm{H}_{2}}=i_{V, a} /\right.$ $\left.2 \mathrm{~F}, \quad S_{\mathrm{H}_{2} \mathrm{O}}=-i_{V, a} / 2 \mathrm{~F}, \quad S_{\mathrm{O}_{2}}=i_{V, c} / 4 \mathrm{~F}, \quad S_{\mathrm{N}_{2}}=0\right)$. The other parameters are given as follows:

$\mathrm{k}_{i, 1}=\frac{D_{i, K} D_{12}}{D_{12}+D_{m}} \quad \mathrm{k}_{2}=\frac{D_{1, K} D_{2, K}}{P_{\mathrm{T}}\left(D_{12}+D_{m}\right)}+\frac{K}{\mu} \quad D_{m}=x_{1} D_{2, K}+x_{2} D_{1, K} \quad D_{i, K}=\frac{\varepsilon}{\tau} \frac{\mathrm{d}_{\mathrm{p}}}{3} \sqrt{\frac{8 \mathrm{RT}}{\pi \mathrm{M}_{i}}}$ $\mu=\frac{\mu_{1} c_{1} \mathrm{M}_{1}^{0.5}+\mu_{2} c_{2} \mathrm{M}_{2}^{0.5}}{\mu_{1} \mathrm{M}_{1}^{0.5}+\mu_{2} \mathrm{M}_{2}^{0.5}} \quad D_{12}=\frac{\varepsilon}{\tau} \frac{0.00143 \mathrm{~T}^{1.75}}{P_{\mathrm{T}} \mathrm{M}_{12}\left(V_{1}^{1 / 3}+V_{2}^{1 / 3}\right)^{2}} \quad \mathrm{M}_{12}=\frac{2}{\mathrm{M}_{1}^{-1}+\mathrm{M}_{2}^{-1}}$

where $x_{i}$ is the molar fraction, $\mu_{i}$ the viscosity and $\mathrm{M}_{i}$ the molecular weight of gas species $i$, dp is the mean pore diameter, $\varepsilon$ the porosity and $\tau$ the pore tortuosity, $V i$ is the special Fuller et al. diffusion volume. $K$ is the permeability of the porous electrode, evaluated using the BlakeKozeny relation: $K=1 / 72 \tau \times\left(\mathrm{d}_{\mathrm{p}} \varepsilon /(1-\varepsilon)\right)^{2}$.

$D_{i, K}$ and $D_{12}$ are effective diffusivities for, respectively, Knudsen and binary diffusion. All gas-related parameters can be found in (17). Reactions rates of the electrochemical semireactions, taking place at each electrode, are expressed by the well-known macro-kinetic Butler-Volmer equation:

$$
i_{V}=i_{\mathrm{tpb}} \lambda_{\mathrm{tpb}}\left[\exp \left(\frac{\beta \mathrm{nF}}{\mathrm{RT}} \eta_{\mathrm{act}}\right)-\exp \left(-\frac{(1-\beta) \mathrm{nF}}{\mathrm{RT}} \eta_{\mathrm{act}}\right)\right]
$$

The parameters intervening here are different in the anodic and cathodic compartments. $i_{V}\left(\mathrm{Am}^{-3}\right)$ is the volumetric current density, coupling the transport equations for gas species and ions as a source/sink term (see eq. ). $\eta_{\text {act }}$ is the local activation overpotential and $n$ the number of electrons participating in the electrochemical semi-reaction. $\beta$, the transfer coefficient, is assumed to be 0.5 . $i_{\mathrm{tpb}}$ is the exchange current rate per unit TPB length $(\mathrm{A} / \mathrm{m})$ and $\lambda_{\mathrm{tpb}}$ the TPB length density in the electrode $\left(\mathrm{m}^{-2}\right)$. Empirical equations can be used for calculating $i_{\mathrm{tpb}}$ for the anode (18) and in the cathode (19) respectively: 
anode: $i_{\mathrm{tpb}}=31.4 P_{\mathrm{H}_{2}}^{-0.03} P_{\mathrm{H}_{2} \mathrm{O}}^{0.4} \exp \left(-\frac{18300}{\mathrm{~T}}\right) \quad$ cathode: $i_{\mathrm{tpb}}=1.1 P_{\mathrm{O}_{2}}^{0.5} \exp \left(-\frac{16500}{\mathrm{~T}}\right)$

Using the estimation performed in different papers for $\lambda_{\text {tpb }}$ (12), (20), (21), (22), the value $1.8 \times 10^{12}\left[\mathrm{~m}^{-2}\right]$ was chosen. Activation overpotentials are defined as:

$$
\text { anode: } \eta_{\mathrm{act}}=\phi_{\mathrm{e}, \mathrm{a}}-u-\mathrm{E}_{\mathrm{a}} \quad \text { cathode: } \eta_{\mathrm{act}}=\mathrm{E}_{\mathrm{c}}-\left(\phi_{\mathrm{e}, \mathrm{c}}-u\right)
$$

where $\phi_{\mathrm{e}}$ and $\mathrm{u}$ represent the electronic the ionic potentials. Ea and Ec refer to electrode equilibrium potentials, which can be expressed as

$$
\mathrm{E}_{\mathrm{a}}=-\frac{\mathrm{RT}}{2 \mathrm{~F}} \ln \frac{P_{\mathrm{H}_{2}}}{P_{\mathrm{H}_{2} \mathrm{O}}}, \quad \mathrm{E}_{\mathrm{c}}=\mathrm{E}_{\mathrm{OC}}+\frac{\mathrm{RT}}{4 \mathrm{~F}} \ln P_{\mathrm{O}_{2}}
$$

The cell operating voltage $\left(\mathrm{E}=\phi_{\mathrm{e}, \mathrm{a}}-\phi_{\mathrm{e}, \mathrm{c}}\right)$ is fixed at $0.7 \mathrm{~V}$ for all simulations as a boundary condition. The values of the simulation parameters are given in Table II.

After appropriate meshing of the simulation domains, the problem was solved for the five unknowns $\left(u, P_{\mathrm{H}_{2}}, P_{\mathrm{H}_{2} \mathrm{O}}, P_{\mathrm{O}_{2}}, P_{\mathrm{N}_{2}}\right)$. The total current produced was then calculated as an integral over the anodic domain $\mathrm{AV}: \mathrm{I}_{\mathrm{T}}=\int_{\mathrm{AV}} i_{V} \mathrm{~d} x \mathrm{~d} y$. This value has been normalized with respect to the length of the simulation domain to finally get the density of produced current per unit cell length $(\mathrm{A} / \mathrm{m})$, namely Idens $=\mathrm{I}_{\mathrm{T}} / 2(\mathrm{D}+\mathrm{L})$. Its value represents the performance indicator which will be used in the following analysis. Boundary conditions are summarized in Table III. Here, boundaries are identified through cardinal points, with reference to the scheme in Figure.1, right.

\begin{tabular}{|c|c|}
\hline Parameter & Value [Units] \\
\hline $\mathrm{T}$ (temperature) & $800\left[{ }^{\circ} \mathrm{C}\right]$ \\
\hline$\varepsilon$ (porosity) & anode: 0.33 , cathode: 0.5 \\
\hline $\mathrm{V}_{\mathrm{YSZ}}$ (YSZ vol. frac.) & anode: 0.33 , cathode: 0.25 \\
\hline$\tau_{\mathrm{YSZ}}(\mathrm{YSZ}$ tortuosity) & 3 \\
\hline$\sigma_{\mathrm{YSZ}}^{0}$ (bulk YSZ conduct.) & $3.3410^{4} \mathrm{e}^{(-10300 / T)}\left[\mathrm{Sm}^{-1}\right]$ \\
\hline$\sigma_{\mathrm{YSZ}}^{\text {eff }}$ (effective YSZ conduct.) & $\sigma_{\mathrm{YSZ}}^{0} \times \mathrm{V}_{\mathrm{YSZ}} \times \tau_{\mathrm{YSZ}}$ \\
\hline$\lambda_{\text {tpb }}$ (TPB density length) & $1.810^{12}\left[\mathrm{~m}^{-2}\right]$ \\
\hline $\mathrm{d}_{\mathrm{p}}$ (mean particle diameter) & $2[\mu \mathrm{m}]$ \\
\hline
\end{tabular}

TABLE II. Simulation parameters.

TABLE III. Boundary conditions: $\mathrm{P}$ is the total pressure, $u$ the ionic potential, $e$ the electronic potential.

\begin{tabular}{|l|l|}
\hline Boundary & Conditions \\
\hline Cathode $(\mathrm{N})$ & $\mathrm{P}=1 \mathrm{~atm}(21 \% \mathrm{O} 2+79 \% \mathrm{~N} 2) ; \operatorname{grad}(u)=0 ; e=0$ \\
\hline Anode $(\mathrm{S})$ & $\mathrm{P}=1 \mathrm{~atm}(97 \% \mathrm{H} 2+3 \% \mathrm{H} 2 \mathrm{O}) ; \operatorname{grad}(u)=0 ; e=\mathrm{E}$ \\
\hline All sides $(\mathrm{E}, \mathrm{W})$ & Periodic \\
\hline
\end{tabular}

Results and discussion

The effect of geometrical parameters on the performance of the assembly was studied, with the aim of finding guidelines for the optimization of the patterned interface. The model was 
run for all possible combinations of the geometric parameters. As already mentioned, for each kind of pattern (ellipse, triangle and rectangle), 96 simulations were performed and the series of Idens were recorded. Each result was then compared with the corresponding reference case $(\mathrm{Te}=50$ or $80 \mu \mathrm{m})$ and the percentage $\Delta \mathrm{I}=100 *$ (Idens - Idens,ref)/ Idens, ref was calculated. $\Delta \mathrm{I}$ represents the current percentage increment with respect to the reference (flat interface) case. Therefore, its value is a good measure of the performance of the pattern. Table IV shows the geometries presenting the best performances for the two values of Te tested. The ellipse and the triangle show almost equivalent performances and the rectangle come in third place.

TABLE IV. Best geometries.

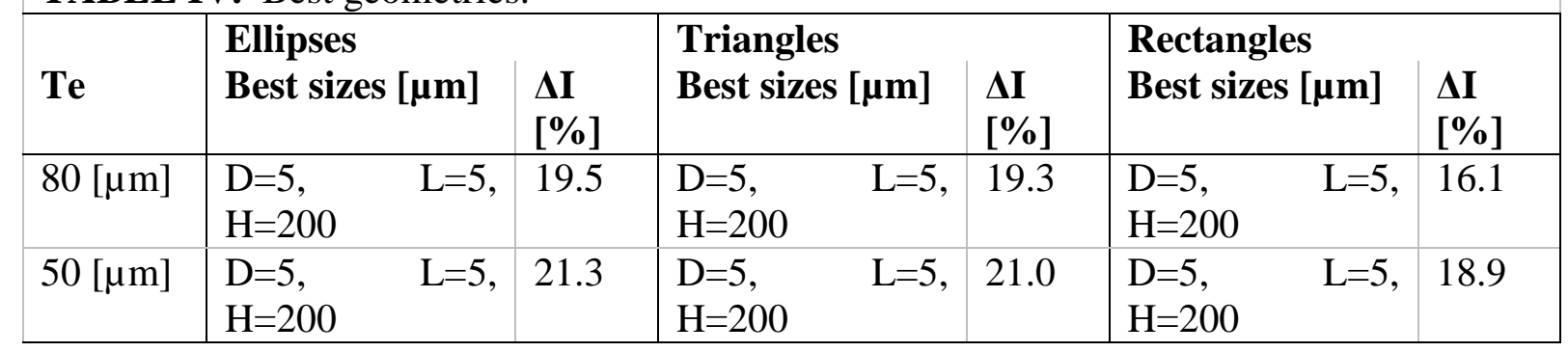

The effects of the geometrical parameters of the pattern on cell performance are shown in figure 2. Here, $\Delta \mathrm{I}$ is interpolated in the $2 \mathrm{D}$ charts as a function of $\mathrm{H}$ and $\mathrm{L}$, while $\mathrm{Te}$ and $\mathrm{D}$ are fixed at, respectively, 80 and $10 \mu \mathrm{m}$. The whole set of combinations of the geometrical parameters shown in Table I was simulated, but only a part of them could be displayed in Fig. 2. The geometry of the pattern has its best effect for small $\mathrm{L}(<10 \mu \mathrm{m})$ and large $\mathrm{H}(>100$ $\mu \mathrm{m})$. On the other hand, the effect can be negative when geometry is not optimized (e.g. for large L), leading to a decrease in overall cell performances. Elliptic and triangular patterns seems to perform better than the rectangular ones. Results for other values of $\mathrm{D}$ and Te, not displayed here, show that the best performance is obtained for small values of $\mathrm{D}(<10 \mu \mathrm{m})$. As shown in Table IV, the maximum increment achievable with the patterned interface increases to even greater values for a smaller Te, in accordance to the tendencies found in (13).
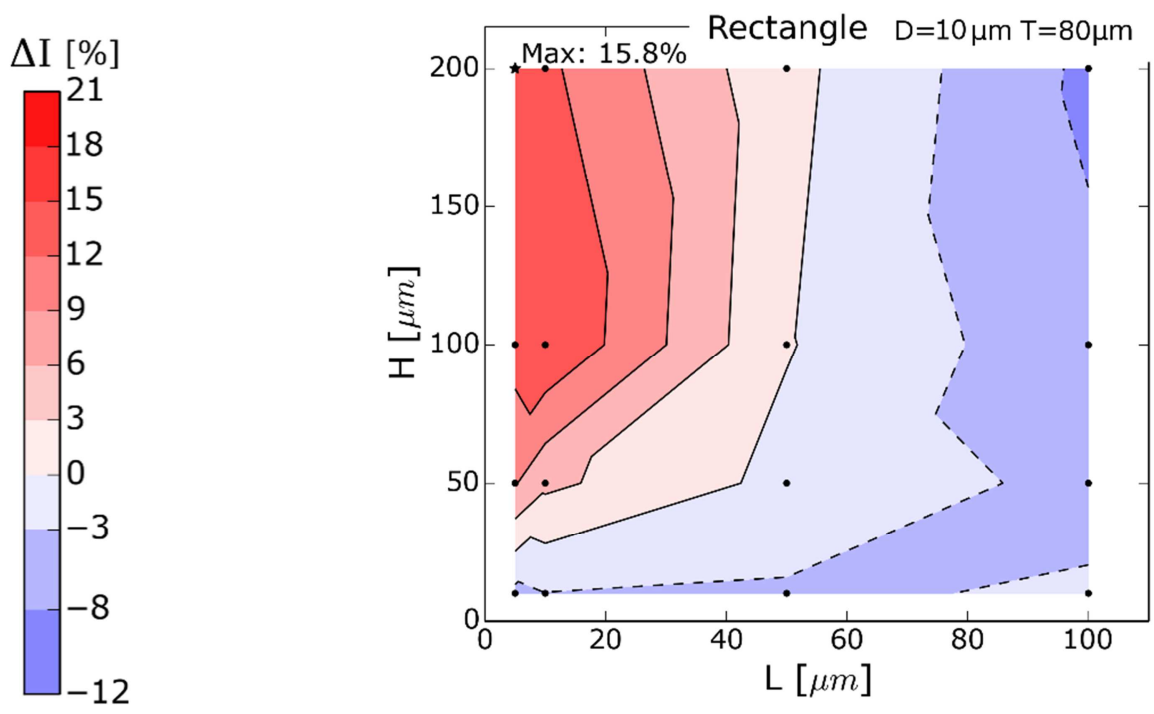

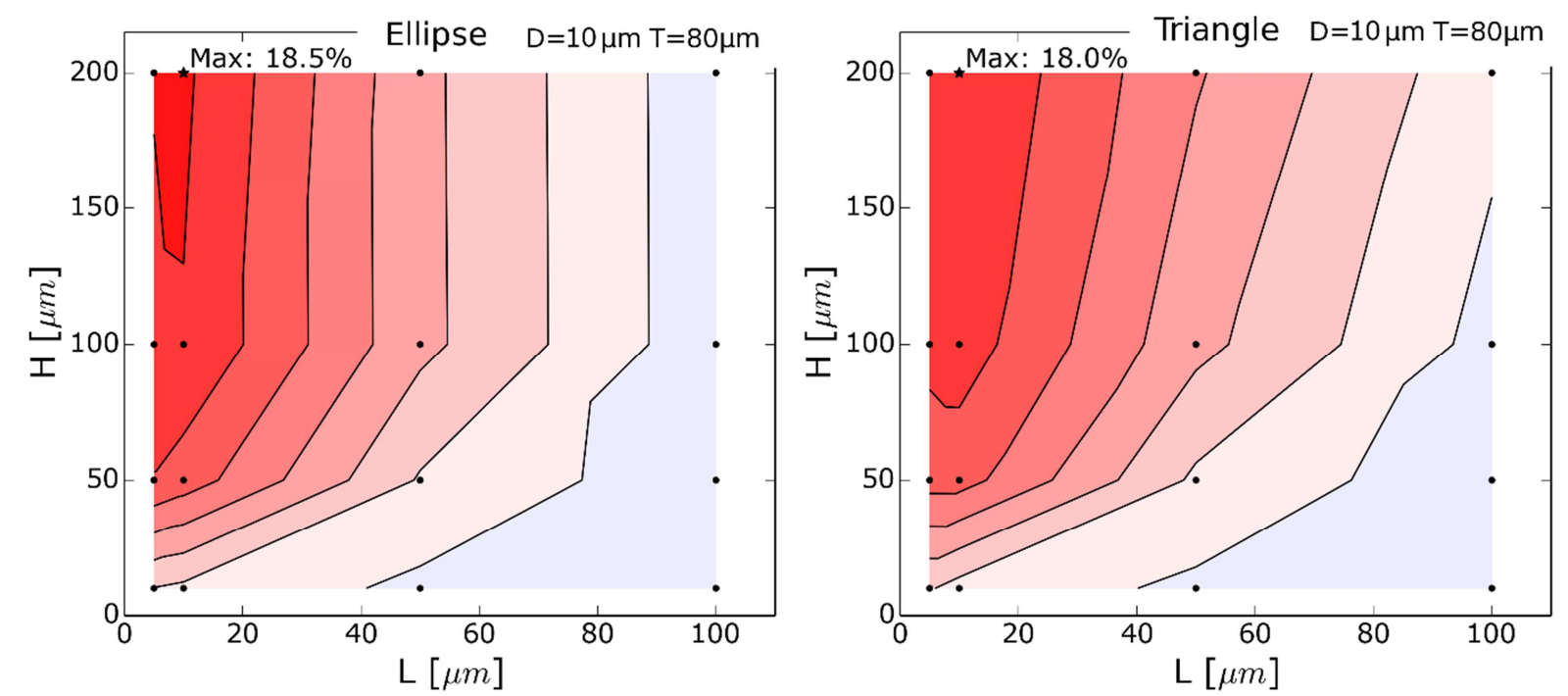

Figure 2. $2 \mathrm{D}$ charts showing $\Delta \mathrm{I}$ variations as a function of $\mathrm{L}$ and $\mathrm{H}$ at fixed $\mathrm{Te}$ and $\mathrm{D}$.

The entire set of simulation results is shown in figure 3 . Here, each vertical line correspond to a given combination of the geometrical parameters. The figure was assembled in the following way. First, an incremental integer was assigned to each combination. This mapping of the geometries on a 1D variable was done following increasing values of $\Delta \mathrm{I}$ for the rectangular series. For each geometry, then, the corresponding values for the triangle and ellipse shapes were added. The three points finally received the same $\mathrm{x}$ coordinate in the plot. As a consequence, the figure should be read by vertical lines when comparing different pattern types at fixed geometrical parameters. It can also be read "horizontally", to find for example the geometries resulting in a given $\Delta \mathrm{I}$ interval. From these results, it can be concluded that the rectangular pattern is the less advantageous in all the cases studied. Although the elliptic pattern shows a slightly better performance in the highest range of $\Delta I$ (extreme right in Figure.3), for several geometrical parameters the optimal section seems to be triangular.

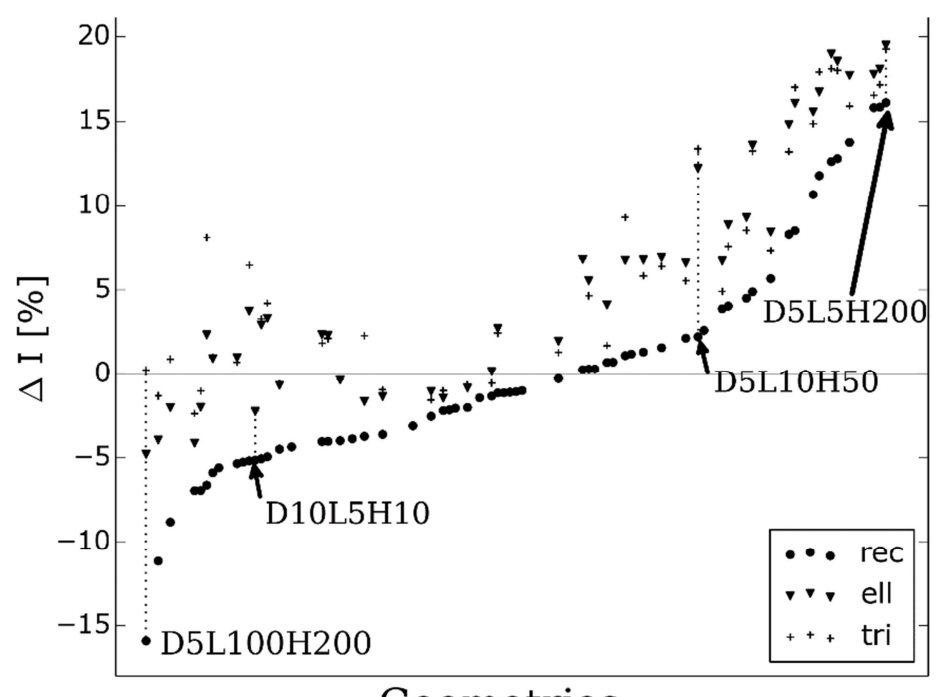

Geometries

Figure.3. Comparison of all simulations. Each $\mathrm{x}$ position correspond to a given vector of geometrical parameters $(\mathrm{Te}, \mathrm{D}, \mathrm{L}, \mathrm{H})$, ordered by the performance index $\Delta \mathrm{I}$ of the rectangle series (circles). 


\section{Conclusions:}

In this paper, a 2-D numerical simulation was performed in order to investigate the effect of geometrical patterns on the cell's performance. Three different patterns with different geometrical parameters each were investigated. The effect of the geometrical parameters of the pattern is found to be crucial for enhancing or worsening the performance an SOFC. Moreover, the effect of the pattern type remains passive, yet vital when geometrical parameters are not fully optimized. Further work will include experimental validation of results through the measurement of the cell's performance culminating in the extension of the model to 3-D simulation.

\section{References:}

1. A.S. Martinez Electrochimica Acta 53 (2008)

2. A. Konno in Heat Transfer-Asian Research, 41 (8), 2012

3. N. Nakagawa J. Electrochem. Soc. 142 (1995)

4. Hiroshi Iwai, Journal of Power Sources 196 (2011)

5. Zhang X, Energy Conversion and Management 48 (2007).

6. T. Kenjo, Solid State Ionics 57 (1992).

7. E.P. Murray, Solid State Ionics 110 (1998) 235-243.

8. V.A.C. Haanappel, J. Power Sources 141 (2005).

9. A. Konno ,Journal of Power Sources 196 (2011)

10. H. Iwaia, Energy 36 (2011)

11. J.H.Nam, Electrochimica Acta 51 (2006)

12. A. Konno, Journal of Power Sources 196 (2011)

13. F.Delloro Journal of Electroceramics 29 (2012)

14. Y.Y. Xie, X.J. Xue J Power Sources, 209 (2012), pp. 81-89

15. Kaka, X.Y.Zhou. International Journal of Hydrogen Energy, 2007, (7):761-786.

16. E.A. Mason, A.P. Malinauskas, R.B. Evans III, J. Chem. Phys. 46 (1967) 3199-3216

17. R. Radhakrishnan, A.V. Virkar, S.C. Singhal, J. Electrochem. Soc. 152 (1) (2005) 210218.

18. Y. Suzue, N. Shikazono, N. Kasagi, J. Power Sources 184 (2008) 52-59.

19. H. Iwai, A. Kuroyanagi, M. Saito, A. Konno, H. Yoshida, T. Yamada, et al. J Power Sources, 196 (2011), pp. 3485-3495

20. M.Andersson, Jinliang Yuan, Bengt Sundén Int J Heat Mass Transfer, 55 (2012), pp. $773-$ 788

21. J. Yuan, Y. Huang, B. Sundén, W.G. Wang, Heat Mass Transfer 45 (2009) 471-484.

22. M. Kishimoto, H. Iwai, M. Saito, H. Yoshida J. Power Sources, 196 (2011), p. 4555, 